\title{
ZIEMNIAKI JAKO POTENCJALNY SUBSTRAT DLA BIOGAZOWNI ROLNICZYCH
}

\author{
Sylwia Bartnikowska*, Wojciech Czekała*, Andrzej Lewicki*, \\ Anna Olszewska*, Anna Smurzyńska*, Michat Brzoski* \\ *Instytut Inżynierii Biosystemów Uniwersytetu Przyrodniczego w Poznaniu \\ Dyrektor Instytutu: prof. dr hab. inż. Jacek Przybył \\ ${ }^{* *}$ Wydział Elektryczny Politechniki Poznańskiej \\ Dziekan Wydziału: dr hab. inż. Zbigniew Nadolny, prof. nadzw.
}

\begin{abstract}
Słowa kluczowe: biogaz, energia elektryczna, fermentacja metanowa, ziemniak Key words: biogas, electric energy, methane fermentation, potato

S y n o p s i s. Ziemniak jest zaliczany do surowców roślinnych mających wszechstronne zastosowanie, począwszy od branży spożywczej, aż do wykorzystania przy produkcji pasz. Klasyfikuje się go zarówno do roślin jadalnych, pastewnych, jak i przemysłowych. Odpady z przetwórstwa ziemniaków można wykorzystać do celów energetycznych, m.in. do wytwarzania paliw ciekłych czy skojarzonej produkcji energii elektrycznej i cieplnej z biogazu powstałego w wyniku fermentacji metanowej. Badania wydajności biogazowej dla czterech prób substratów przeprowadzono zgodnie z obowiązującą niemiecką normą DIN 38 414/S8 w Pracowni Ekotechnologii na Uniwersytecie Przyrodniczym w Poznaniu.
\end{abstract}

\section{WSTĘP}

Ziemniak (łac. Solanumtuberosum) to surowiec roślinny z rodziny psiankowatych [Hijmans 2001], który na kontynent europejski został sprowadzony w XVI wieku przez Hiszpanów, tuż po podboju Państwa Inków. Dopiero dzięki Brytyjczykom zaczęto uprawiać ziemniaki na większą skalę i doceniać ich właściwości kulinarne [Baranowski 1960]. W całej Unii Europejskiej areał uprawy ziemniaków w 2015 r. wyniósł 1,64 mln ha [Agencja Rynku Rolnego 2015]. Warto podkreślić, że do czołowych producentów ziemniaków należy Polska (359 tys. ha) i plasuje się na drugim miejscu, zaraz za Niemcami (238 tys. ha). Termin „ziemniak” odnosi się do całej rośliny, składającej się z części nadziemnej (łodyga, liście, kwiaty, owoce) oraz podziemnej (stolony z bulwami). Zdarza się, że określa się w ten sposób również jadalne elementy rośliny, a więc bulwy.

Na jakość i wykorzystanie bulw wpływa ich skład chemiczny, który jest uwarunkowany genetycznie i różnicowany w głównej mierze przez warunki środowiskowe, genotyp oraz agrotechnikę [Leszczyński 2000]. Głównym składnikiem charakteryzowanej rośliny jest woda, która stanowi około $70 \%$ składu bulw. Skrobia, stanowiąca 17\% składu, czyni ziemniaka dobrym źródłem energii. W śladowych ilościach $(0,5 \%)$ występują cukry proste ulegające fermentacji alkoholowej (glukoza) oraz substancje mineralne (1\%) [Leszczyń- 
ski 2004]. Współcześnie dominuje przemysłowe wykorzystanie ziemniaków (około 40\% produkcji) nad ich konsumpcją (23,5\%) [Leszczyński 2012].

Ziemniaki znalazły zastosowanie w różnych gałęziach przemysłu. Głównymi kierunkami przetwarzania tego surowca są produkcja skrobi oraz etanolu. W postaci naturalnej skrobia ziemniaczana jest rzadko stosowana w przeciwieństwie do jej komponentów, które znajdują wiele zastosowań w przemyśle spożywczym, papierniczym (sklejanie włókien), farmaceutycznym, włókienniczym (składnik osnowy), chemicznym (produkcja opakowań biodegradowalnych). Warte uwagi jest wykorzystanie skrobi w przemyśle ciężkim, np. w górnictwie (flotacja mułu) czy też hutnictwie (lepiszcze do mas formierskich) [Grudzińska 2008]. Od 2 do 3\% produkcji ziemniaka kierowane jest do produkcji biopaliwa płynnego, jakim jest etanol [Zgórska 2010]. Bez wątpienia ziemniak jest wartościowym surowcem, lecz jego wykorzystanie determinuje przede wszystkim jego cena w porównaniu do innych surowców [Nowacki 2004].

Komisja Europejska uznała ziemniak za roślinę energetyczną, jeżeli jest ona celowo uprawiana do przemysłowego przetwarzania na bioetanol lub jest wykorzystana na cele energetyczne w gospodarstwie [Nowacki 2004]. Aby wykorzystać właściwości energetyczne ziemniaka, należy wybrać odmianę dobrze plonującą i wysokoskrobiową. Aktualnie na dużą skalę przetwórstwo ziemniaków jest stosowane do produkcji alkoholu [Marks 2012].

Biogazownia rolnicza to instalacja technologiczna, w której poprzez fermentację substancji organicznych produkuje się biogaz. Oprócz takich składników, jak dwutlenek węgla, azot, siarkowodór, głównym składnikiem biogazu jest metan, którego spalanie pozwala uzyskać energię elektryczną oraz ciepło. Funkcjonowanie biogazowni oraz przebieg fermentacji metanowej są zagadnieniami złożonymi. Elementy instalacji technologicznej (wielkość zbiorników, moc agregatów itp.) do produkcji biogazu są dobierane indywidualnie i dopasowywane głównie do rodzaju i ilości dostępnego substratu wsadowego. Kluczowe znaczenie mają również uwarunkowania ekonomiczne, decydujące o opłacalności danej inwestycji. W zależności od rodzaju substratu odpad trafia do silosów (podajników), następnie jest dozowany do komory fermentacyjnej, gdzie zachodzi beztlenowy rozkład substancji organicznych. W zależności od liczby etapów procesu fermentacji metanowej wyróżnia się trzy opcje technologiczne: fermentację jednoetapową, dwuetapową oraz wieloetapową. Jedną z ważniejszych kwestii jest utrzymanie stałej i odpowiedniej temperatury przez cały okres prowadzenia procesu. Temperaturę procesu dobiera się do rodzaju wprowadzanych bakterii, w celu zwiększenia ich aktywności. Fermentacja metanowa może zachodzić w temperaturze poniżej $25^{\circ} \mathrm{C}$ - jest to fermentacja psychrofilowa, która trwa, co najmniej 70-80 dni. Większość bakterii jest mezofilowa, dlatego najczęściej wykorzystywana jest fermentacja mezofilna, zachodząca w temperaturze $30-40^{\circ} \mathrm{C}$ i trwająca około 30 dni. W wypadku bakterii termofilowych fermentacja trwa najkrócej, jest to zazwyczaj 15-20 dni w temperaturze powyżej $40^{\circ} \mathrm{C}$. Dodatni bilans energii oraz największy uzysk biogazu otrzymywany jest w fermentacji mezofilowej. W zależności od zawartości suchej masy w substratach stosuje się fermentację mokrą oraz fermentację suchą. Biogazownia składa się również ze zbiornika pofermentacyjnego lub laguny, do której trafia pozostałość po procesie fermentacji metanowej w postaci pulpy pofermentacyjnej. W skład układu kogeneracyjnego wchodzą silnik gazowy i generator elektryczny, które produkują energię elektryczną i cieplną. Sprawność zachodzącej przemiany wynosi 90\%, odpowiednio około $45 \%$ energii elektrycznej i około 48\% energii cieplnej [Tytko 2014, Kowalczyk-Juśko 2013, Czerwińska 2012]. 


\section{CEL BADAŃ, MATERIAŁ BADAWCZY I METODYKA BADAŃ}

Celem badań było określenie wydajności biogazowej uzyskiwanej z różnych postaci ziemniaków oraz przeprowadzenie analizy ekonomicznej dotyczącej opłacalności inwestycji w elektrownię biogazową.

Materiał badawczy stanowiły: (I) ziemniaki w stanie surowym, (II) ziemniaki uparowane, (III) skórki ziemniaków w stanie surowym oraz (IV) uparowane skórki ziemniaków. Substrat pochodził z jednego gospodarstwa rolnego zlokalizowanego na terenie województwa wielkopolskiego. We wstępnym etapie doświadczenia substraty zostały odpowiednio rozdrobnione oraz przygotowane do badań.

Mezofilową zaszczepkę bakteryjną uzyskano w procesie odseparowania frakcji ciekłej, pozostałości po procesie fermentacji metanowej-pofermentu $\mathrm{z}$ funkcjonującej biogazowni rolniczej [Pilarski i in. 2012, Kozłowski i in. 2015].

W Pracowni Ekotechnologii Instytutu Inżynierii Biosystemów Uniwersytetu Przyrodniczego w Poznaniu oznaczono podstawowe parametry według metodyki polskich norm (PN): suchą masę metodą wagową: PN-75/C-04616.01, zawartość suchej masy organicznej: PN-Z-15011-3, pH PN-90 C-04540/01 oraz konduktywność PN-EN 27888:1999.

Wydajność biogazową określono zgodnie z niemiecką normą DIN 38 414/S8 oraz znormalizowanym poradnikiem biogazowym Stowarzyszenia Inżynierów Niemieckich w Dreźnie VDI 4630 wykorzystywanym w Pracowni Ekotechnologii Uniwersytetu Przyrodniczego w Poznaniu. Stanowisko fermentacyjne stanowiły reaktory o pojemności $2 \mathrm{dm}^{3}$. Dla fermentacji mezofilowej reaktory zostały umieszczone w łaźni wodnej o temperaturze $39^{\circ} \mathrm{C}$. Reaktory wykorzystane podczas badań stanowią część 21-reaktorowych stanowisk badawczych, które zostały opracowane przez pracowników laboratorium Ekotechnologii. Analizy jakościową i ilościową wyprodukowanego biogazu przeprowadzono za pomocą analizatora gazowego GA5000 firmy Geotech. Pomiary ilościowe oraz jakościowe odbywały się codziennie.

\section{WYNIKI I DYSKUSJA}

Podstawowe parametry wykorzystanych w doświadczeniu substratów zestawiono w tabeli 1 . Na podstawie danych z tabeli 1. można stwierdzić, że wartości wszystkich czterech badanych parametrów były do siebie zbliżone. Badane substraty charakteryzowały się niską zawartością suchej masy na poziomie 22-28\%. Zawartość suchej masy organicznej była wysoka i zawierała się w przedziale $94-96 \%$. Potwierdza to przydatność badanych substratów do produkcji biogazu, gdyż właśnie z przemian materii organicznej powstaje metan. Najwyższą wartość suchej masy organicznej odnotowano w ziemniaku w stanie surowym.

Głównym substratem wykorzystywanym w biogazowniach jest kiszonka z kukurydzy. Uzyskane wyniki suchej masy oraz suchej masy organicznej w przeprowadzonym badaniu były zbliżone do parametrów kiszonki z kukurydzy (sucha masa 20-36\% ś.m., sucha masa organiczna $85-96 \%$ ś.m.).

Zgodnie z danymi literaturowymi zawartość suchej masy w liściach ziemniaków mieści się w przedziale 22-26\%, w niej udział suchej masy organicznej wynosi zwykle 70-80\%. Analizując ziemniaki jako całość, zawartość suchej masy w świeżej masie osiąga poziom $20,1 \%$, a odsetek suchej masy organicznej w suchej masie 92,2\% [Romuniak, Domasiewicz 2014]. Wyniki badań dotyczące produkcji biogazu z ziemniaków, zaprezentowane 
Tabela 1. Wartość suchej masy, suchej masy organicznej, pH i konduktywności badanych substratów

\begin{tabular}{lcccc}
\hline Rodzaj próbki & $\begin{array}{c}\text { Sucha masa } \\
{[\%]}\end{array}$ & $\begin{array}{c}\text { Sucha masa } \\
\text { organiczna [\%] }\end{array}$ & $\mathrm{pH}$ & $\begin{array}{c}\text { Konduktywność } \\
{[\mathrm{mS} / \mathrm{cm}]}\end{array}$ \\
\hline Ziemniaki w stanie surowym & 22,50 & 95,36 & 8,07 & 8,61 \\
Ziemniaki uparowane & 25,88 & 95,04 & 8,07 & 8,08 \\
Skórki ziemniaków & 22,35 & 92,13 & 8,02 & 7,63 \\
w stanie surowym & 27,80 & 94,08 & 8,00 & 9,48 \\
Uparowane skórki ziemniaków & & & & \\
\hline
\end{tabular}

Źródło: badania własne.

przez Andrzeja Myczko z zespołem, wykazały, że największą zawartością suchą masy charakteryzowały się łęty ziemniaków (22-26\%), łupiny (10-15\%), a najmniejszą - sok ziemniaczany (4-6\%), ale poszczególne części ziemniaków są zwykle mniej zasobne W suchą masę w porównaniu do kiszonki z kukurydzy (20-36\%) [Myczko i in. 2011]. Również większych uzysków można się spodziewać w przypadku wykorzystania buraków cukrowych - zawartość suchej masy w 1 tonie substratu osiąga poziom 13,5\%, zawartość suchej masy organicznej w zawartości suchej wynosi około 85\% [Curkowski, Oniszk-Popławska 2010].

Odczyn pH we wszystkich próbkach był lekko zasadowy, a wartość parametru mieściła się w zakresie 8,00-8,07. Najwyższymi wartościami charakteryzowały się ziemniaki, niezależnie, czy były surowe, czy uparowane. Konduktywność skórek ziemniaków w stanie surowym przedstawiała najmniejszą wartość $(7,63 \mathrm{mS} / \mathrm{cm})$, najwyższą wartością $(9,48 \mathrm{mS} / \mathrm{cm})$ zaś odznaczały się uparowane skórki ziemniaków. Jednak wartość we wszystkich czterech próbkach była stosunkowo wysoka, co świadczy o zasobności substratów w związki mineralne.

\section{WYDAJNOŚĆ BIOGAZOWA ORAZ METANOWA ANALIZOWANYCH SUBSTRATÓW}

W tabeli 2. przedstawiono wyniki pomiaru biogazu badanych substratów. Dla ziemniaków w stanie surowym zawartość metanu wynosiła 47,73\%, a z 1 tony świeżej masy otrzymano około $171 \mathrm{~m}^{3}$ biogazu. Dla ziemniaków uparowanych zawartość metanu była niższa i wynosiła $42,5 \%$.

Skórki ziemniaków w stanie surowym charakteryzowały się największą zawartością metanu na poziomie $48,42 \%$. Dla tej postaci ziemniaków z 1 tony świeżej masy można uzyskać około $139 \mathrm{~m}^{3}$ biogazu. Z kolei uparowane skórki ziemniaków miały zawartość metanu $46 \%$, a z 1 tony świeżej masy otrzymano około $165 \mathrm{~m}^{3}$ biogazu. Według Wacława Romuniaka i Tadeusza Domasiewiczaz zawartość metanu w ziemniakach wynosiła średnio 56,5\%. Uzysk biogazu z 1 tony świeżej masy ziemniaków kształtował się na poziomie $134 \mathrm{~m}^{3}$ [Romuniak, Domasiewicz 2014]. W badaniach pod kierunkiem A. Myczko największą wydajność biogazu uzyskano z łętów ziemniaka (80-120 $\left.\mathrm{m}^{3}\right)$, a udział metanu osiągnął wartość 52-56\%. Porównując je z innymi częściami ziemniaczanymi - z łupinami $\left(35-42 \mathrm{~m}^{3}\right.$ z 1 t ś.m.; $\mathrm{CH}_{4}: 25-44 \%$ ) czy też sokiem ziemniaczanym (6,5-15 m³ z 1 t ś.m.; $\left.\mathrm{CH}_{4}: 55-60 \%\right)$, to właśnie łęty okazały się korzystniejszym substratem do fermentacji metanowej. Najwyż- 
Tabela 2. Wyniki pomiaru biogazu dla badanych substratów

\begin{tabular}{|c|c|c|c|c|c|c|c|}
\hline \multirow{2}{*}{$\begin{array}{l}\text { Rodzaj } \\
\text { substratu }\end{array}$} & \multicolumn{3}{|c|}{ Metan skumulowany } & \multicolumn{3}{|c|}{ Biogaz skumulowany } & \multirow{2}{*}{$\begin{array}{c}\text { Zawartość } \\
\text { metanu } \\
{[\%]}\end{array}$} \\
\hline & $\begin{array}{c}\text { świeża } \\
\text { masa } \\
{\left[\mathrm{m}^{3} / \mathrm{t}\right.} \\
\text { ś.m. }]\end{array}$ & $\begin{array}{l}\text { sucha } \\
\text { masa } \\
{\left[\mathrm{m}^{3} / \mathrm{t}\right.} \\
\text { s.m. }]\end{array}$ & $\begin{array}{c}\text { sucha masa } \\
\text { organiczna } \\
{\left[\mathrm{m}^{3} / \mathrm{t}\right.} \\
\text { s.m.o] }\end{array}$ & $\begin{array}{c}\text { świeża } \\
\text { masa } \\
{\left[\mathrm{m}^{3} / \mathrm{t}\right.} \\
\text { ś.m. }]\end{array}$ & $\begin{array}{l}\text { sucha } \\
\text { masa } \\
{\left[\mathrm{m}^{3} / \mathrm{t}\right.} \\
\text { s.m. }]\end{array}$ & $\begin{array}{c}\text { sucha masa } \\
\text { organiczna } \\
{\left[\mathrm{m}^{3} / \mathrm{t}\right.} \\
\text { s.m.o }]\end{array}$ & \\
\hline $\begin{array}{l}\text { Ziemniaki } \\
\text { w stanie } \\
\text { surowym }\end{array}$ & 81,83 & 363,66 & 381,36 & 171,45 & 761,98 & 799,06 & 47,73 \\
\hline $\begin{array}{l}\text { Ziemniaki } \\
\text { uparowane }\end{array}$ & 39,40 & 152,25 & 160,19 & 92,46 & 357,24 & 375,89 & 42,62 \\
\hline $\begin{array}{l}\text { Skórki } \\
\text { ziemniaków } \\
\text { w stanie } \\
\text { surowym }\end{array}$ & 67,50 & 302,05 & 327,84 & 139,40 & 626,13 & 677,06 & 48,42 \\
\hline $\begin{array}{l}\text { Uparowane } \\
\text { skórki } \\
\text { ziemniaków }\end{array}$ & 76,180 & 274,01 & 291,26 & 165,62 & 595,69 & 633,18 & 46,00 \\
\hline
\end{tabular}

Źródło: badania własne.

sze wyniki osiąga się w przypadku kiszonki z kukurydzy, dla której efektywność biogazowa oscyluje w zakresie 170-200 $\mathrm{m}^{3} \mathrm{z} 1$ tony świeżej masy substratu, a udział metanu wynosi zwykle 52-56\% [Myczko 2011].

\section{EFEKTYWNOŚĆ EKONOMICZNA}

Powierzchnia upraw ziemniaka w Polsce to około 13\% ogólnej powierzchni zasiewów, co pod względem wielkości obszaru daje trzecie miejsce, zaraz po uprawie pszenicy i żyta. Ziemniaki można uprawiać na glebach słabych, jednak nie tolerują one nadmiaru wilgoci oraz w okresie dojrzewania niskich temperatur. Ponad 95\% areału uprawy ziemniaków znajduje się w gospodarstwach rolników indywidualnych, ze względu na dużą pracochłonność związaną z pielęgnacją podczas procesu dojrzewania. W Polsce dominujące tereny uprawy ziemniaka to Mazowsze, Podlasie, wschodnia Wielkopolska, Wysoczyzna Piotrowska, Karpaty i Podkarpacie.

W Wielkopolsce ziemniak uprawia się na powierzchni 31809 ha (ponad 90\% w gospodarstwach indywidualnych). Plon wynosi około 20 t/ha, a średnia wielkość plantacji w gospodarstwie rolnym uprawiającym ziemniaki wynosi około 0,7 ha, co daje $14 \mathrm{t}$ ziemniaków z jednego gospodarstwa.

Analizę ekonomiczną przeprowadzono na podstawie metodyki zaproponowanej dla biogazowni przez Roberta Szulca i Jacka Dacha [Szulc, Dach (red.) 2014]. Przyjęto następujące założenia:

1) podstawowe substraty stanowiące wkład biogazowni to gnojowica bydlęca (9,5\% s.m.; 78,5\% s.m.o.; $390 \mathrm{~m}^{3} / \mathrm{t}$ s.m.o.; $\left.\mathrm{S}_{\mathrm{CH} 4}=52,5 \%\right)$ i kiszonka z kukurydzy (28\% s.m.; 90,5\% s.m.o.; $575 \mathrm{~m}^{3} / \mathrm{t}$ s.m.o.; $\mathrm{S}_{\mathrm{CH} 4}=42,5 \%$ ) [Myczko i in. 2011],

2) uzupełnienie wyżej wymienionych substratów to ziemniaki w stanie surowym $(22,5 \%$ s.m.; 95,36\% s.m.o.; 799,06 m³/t s.m.o.; $\mathrm{S}_{\mathrm{CH} 4}=47,73 \%$ ), 
3) koszt instalacji biogazowej (o mocy 0,164 MW - 3,3 mln zł,

4) inwestor ma gotówkę na inwestycję, nie korzysta $\mathrm{z}$ dotacji oraz kredytów,

5) czas eksploatacji biogazowni - 15 lat,

6) stała stopa dyskonta $-5 \%$,

7) inwestor dysponuje poszczególnymi materiałami wsadowymi w ilości: gnojowica bydlęca -8000 t/rok, kiszonka z kukurydzy - 3000 t/rok surowe ziemniaki - 14 t/rok (0,7 ha razy 20 t/ha). Łączna ilość substratów wyniesie 11014 t w ciągu roku.

$\mathrm{W}$ tabeli 3. zestawiono dane dotyczące parametrów energetycznych instalacji oraz roczne przychody i koszty jej funkcjonowania.

Tabela 3. Zestawienie parametrów energetycznych instalacji oraz roczne przychody i koszty jej funkcjonowania

\begin{tabular}{|c|c|}
\hline Wyszczególnienie & Wielkość \\
\hline \multicolumn{2}{|l|}{ Parametry energetyczne instalacji } \\
\hline Całkowita objętość biogazu $\left[\mathrm{m}^{3}\right]$ & 672186,18 \\
\hline Całkowita objętość metanu $\left[\mathrm{m}^{3}\right]$ & 309071,9 \\
\hline Energia elektryczna [MWh] & 1190,36 \\
\hline Energia cieplna [MWh] & 1360,41 \\
\hline Moc elektryczna [MW] & 0,143 \\
\hline Moc cieplna $[\mathrm{MW}]$ & 0,164 \\
\hline \multicolumn{2}{|l|}{ Koszty roczne } \\
\hline Koszt substratów [zł] & 270560 \\
\hline Koszt usług serwisowych [zt] & 173332,52 \\
\hline Koszt amortyzacji [zł] & 330000 \\
\hline Koszt personelu [zł] & 48000 \\
\hline Całkowite koszty [zł] & 821892,52 \\
\hline \multicolumn{2}{|l|}{ Roczne przychody } \\
\hline Przychód ze sprzedaży pofermentu [zł] & 256075,50 \\
\hline Przychód ze sprzedaży $\mathrm{CO}_{2}$ [zł] & 192861,20 \\
\hline Przychód ze sprzedaży energii cieplnej [zł] & 115287,55 \\
\hline Przychód ze sprzedaży energii elektrycznej [zł] & 655888,36 \\
\hline Całkowite przychody z eksploatacji instalacji biogazowej [zł] & 1220112,61 \\
\hline
\end{tabular}

Źródło: opracowanie własne.

Parametry energetyczne instalacji obliczono następująco:

a) objętość wytwarzanego biogazu: $V_{b}=W_{b} \cdot M\left[\mathrm{~m}^{3}\right]$, gdzie: $V_{b}$-objętość wytwarzanego biogazu $\left[\mathrm{m}^{3}\right], W_{b}$ - wydajność biogazowa substratu $\left[\mathrm{m}^{3 /} \mathrm{t}\right], M$ - masa substratu $[\mathrm{t}]$ :

- gnojowica: $V_{b 1}=390\left[\mathrm{~m}^{3} / \mathrm{t}\right.$ s.m.o.] $\cdot 596,6$ [t s.m.o.] $=232574\left[\mathrm{~m}^{3}\right]$,

- kiszonka: $V_{b 2}=675\left[\mathrm{~m}^{3} / \mathrm{t} \mathrm{s.m.o.]} 760,2\right.$ [t s.m.o.] $=437115\left[\mathrm{~m}^{3}\right]$,

- ziemniaki: $V_{b 3}=799,06\left[\mathrm{~m}^{3} / \mathrm{t}\right.$ s.m.o. $] \cdot 3$ [t s.m.o. $]=2397,18\left[\mathrm{~m}^{3}\right]$,

b) objętość biogazu w przeliczeniu na zawartość suchej masy organicznej:

- gnojowica bydlęca:

$8000[\mathrm{t}] \cdot 9,5[\%]=760[\mathrm{t}]$

$760[\mathrm{t}] \cdot 78,5[\%]=596,6,[\mathrm{t}]$ 
- kiszonka z kukurydzy:

$3000[\mathrm{t}] \cdot 28[\%]=840[\mathrm{t}]$

$840[\mathrm{t}] \cdot 90,5[\%]=760,2[\mathrm{t}]$

- $\quad$ surowe ziemniaki:

$14[\mathrm{t}] \cdot 22,5[\%]=3,15[\mathrm{t}]$

$3,15[\mathrm{t}] \cdot 96,36[\%]=3[\mathrm{t}]$

c) objętość metanu: $V_{C H 4}=V_{b} . S_{C H 4}$, gdzie: $V_{C H 4}$ - objętość wytworzonego metanu $\left[\mathrm{m}^{3}\right]$, $V_{b}$ - objętość wytworzonego biogazu $\left[\mathrm{m}^{3}\right], S_{C H 4}$ - stężenie metanu w biogazie [\%]:

- gnojowica $V_{C H 41}=232674\left[\mathrm{~m}^{3}\right] \cdot 0,525=122153,85\left[\mathrm{~m}^{3}\right]$,

- kiszonka $V_{\mathrm{CH}_{4} 2}=437115\left[\mathrm{~m}^{3}\right] \cdot 0,425=185773,788\left[\mathrm{~m}^{3}\right]$.

- ziemniaki $V_{C H 43}=2397,18\left[\mathrm{~m}^{3}\right] \cdot 0,4773=1144,17\left[\mathrm{~m}^{3}\right]$.

Roczny zysk obliczono ze wzoru: $Z=P R Z-K_{i b}$, gdzie: $Z$ - zysk roczny brutto z tytułu eksploatacji biogazowni, $P R Z$ - przychód roczny z tytułu eksploatacji biogazowni, $K_{i b}-$ roczne koszty eksploatacji biogazowni: $Z=1220$ 103,61 zł-821 892,52 zł=398 111,09 zł Poszczególne wartości bieżące netto (NPV) zostały przedstawione w tabeli 4. Wartości te zostały obliczone ze wzoru:

$$
\mathrm{NPV}=\sum_{t=1}^{n} \frac{C F_{t}}{(1+r)^{t}}-I_{0}
$$

gdzie: $N P V$ - wartość bieżąca netto, $C F_{t}$ - przepływy gotówkowe w okresie $t, r$ - stopa dyskonta, $I_{o}$ - nakłady początkowe, $t$ - kolejne lata eksploatacji biogazowni.

Tabela 4. Przepływy pieniężne netto analizowanej inwestycji w zł (stopa dyskonta 5\%)

\begin{tabular}{ccccc}
\hline Lata & Wpływy & Wydatki & $\begin{array}{c}\text { Przepływy pieniężne } \\
\text { netto }\end{array}$ & $\begin{array}{c}\text { Wartość } \\
\text { zaktualizowana }\end{array}$ \\
\hline 1 & 0 & 3300000 & -3300000 & $-3300000,00$ \\
2 & 1220103 & 821892 & 398211 & 379248,57 \\
3 & 1220103 & 821892 & 398211 & 361189,12 \\
4 & 1220103 & 821892 & 398211 & 327609,63 \\
5 & 1220103 & 821892 & 398211 & 312008,74 \\
6 & 1220103 & 821892 & 398211 & 297151,18 \\
7 & 1220103 & 821892 & 398211 & 283001,12 \\
8 & 1220103 & 821892 & 398211 & 269524,88 \\
9 & 1220103 & 821892 & 398211 & 256690,36 \\
10 & 1220103 & 821892 & 398211 & 244467,01 \\
11 & 1220103 & 821892 & 398211 & 232825,72 \\
12 & 1220103 & 821892 & 398211 & 221738,79 \\
13 & 1220103 & 821892 & 398211 & 211179,80 \\
14 & 1220103 & 821892 & 398211 & 201123,61 \\
15 & 1220103 & 821892 & 398211 & 191546,30 \\
Suma & & & & 833294,01 \\
\hline
\end{tabular}

Źródło: obliczenia własne. 
W analizowanym przedsięwzięciu suma zdyskontowanych przepływów pieniężnych netto wynosi $833294,01 \mathrm{zl}$, natomiast wewnętrzna stopa zwrotu (IRR) wynosi 8,54\%. Wykonane obliczenia uzasadniają stwierdzenie, iż budowa i eksploatacja instalacji biogazowej na podstawie przyjętych założeń ma uzasadnienie ekonomiczne. Zwiększenie korzyści finansowych może przynieść skorzystanie ze środków wsparcia dla takiej inwestycji przez udział inwestora w systemie aukcyjnym. Oprócz tego proponuje się zwiększenie zasobów pozyskiwanych substratów - właściciel biogazowni powinien dołożyć starań, by móc uzyskać kolejny darmowy substrat o wysokiej wartości biometanowej, gdyż w ten sposób zwiększy opłacalność budowy i eksploatacji instalacji biogazowej.

\section{WNIOSKI}

1. Ziemniaki z powodzeniem mogą być wykorzystywane do celów energetycznych pod warunkiem, że pochodzą z odmian wysokoskrobiowych oraz upraw celowych przeznaczonych wyłącznie na przetwórstwo przemysłowe.

2. W badaniach analizowano różne postaci ziemniaków, w których mogą zostać podane jako substrat do biogazowni. Najkorzystniejszą formą okazały się skórki ziemniaków w stanie surowym (około 47\% metanu), najmniej korzystną - ziemniaki w całości uparowane $(42,6 \%$ metanu).

3. Dane opublikowane w literaturze przedmiotu wskazują, że łęty ziemniaków okazują się częścią najbardziej przydatną do procesu fermentacji ze względu na uzyskiwane wysokie wydajności biogazowe.

4. Przeprowadzone obliczenia wykazała opłacalność analizowanej biogazowni, co potwierdza roczny zysk w wysokości 398 211,09 zł.

5. Zdyskontowany okres zwrotu wynosi około 11 lat, co wynika z wysokich poniesionych nakładów inwestycyjnych.

\section{LITERATURA}

Agencja Rynku Rolnego, Ministerstwo Rolnictwa i Rozwoju Wsi, „Rynek Ziemniaka. Stan i Perspektywy", nr 3.

Baranowski Bohdan, 1960: Poczatki i rozpowszechnienie uprawy ziemniaków na ziemiach środkowej Polski, Łódzkie Towarzystwo Naukowe, Publikacja nr 32.

Curkowski Andrzej, Anna Oniszk-Popławska, 2010: Surowce do produkcji biogazu - uproszczona metoda obliczenia wydajności biogazowni rolniczej, „Czysta Energia”, nr 1.

Czerwińska Ewa, Katarzyna Kalinowska, 2012: Warunki prowadzenia procesu fermentacji metanowej w biogazowni, „Technika Rolnicza Ogrodnicza Leśna”, nr 2.

Grudzińska Magdalena, Kazimiera Zgórska, 2008: Ziemniak surowcem dla przetwórstwa spożywczego [w] Ziemniaki - nowe perspektywy. Specjalny dodatek do dwutygodnika „AgroSerwis”, Wyd. 2, Biznes Press Warszawa, s. 17-18.

Hijmans Robert, David Spooner, 2001: Geographic distribution of wild potato species, American Journal of Botany, Publikacja nr 88, s. 2101-2112.

Kowalczyk-Juśko Alina, 2013: Biogazownie szansą dla rolnictwa i środowiska, FDPA, Warszawa, s. 1-91.

Kozłowski Kamil, Marta Cieślik, Andrzej Lewicki, Jakub Frankowski, Anna Olszewska, Pablo Cesar Rodriguez Carmona, 2015: Analiza przydatności stomy szarłatu wyniostego jako substratu dla biogazowni, „Inżynieria Środowiska-Młodym Okiem”, t. 11, s. 73-82.

Leszczyński Wacław, 2000: Jakość ziemniaka konsumpcyjnego, „Żywność. Suplement”, nr 4, s. 5. 
Leszczyński Wacław, 2004: Skrobia - surowiec przemysłowy, budowa i właściwości, „Zeszyty Problemowe Postępów Nauk Rolniczych", 500, s. 69-98.

Leszczyński Wacław, 2012: Znaczenie ziemniaka jako produktu żywnościowego oraz w przetwórstwie przemystowym, „Ziemniak Polski”, s. 38-43.

Marks Norbert, 2012: Wartość energetyczna różnych odmian ziemniaka, „Inżynieria Rolnicza”, z. 2(136), t. 1, s. 205-212.

Myczko Andrzej, Renata Myczko, Tomasz Kołodziejczyk, Renata Golimowska, Jakub Lenarczyk, Zygmunt Janas, Andrzej Kliber, Jerzy Karłowski, Mirosława Dolska, 2011: Budowa i eksploatacja biogazowni rolniczych. Poradnik dla inwestorów zainteresowanych budowa biogazowni rolniczych, Wydawnictwo ITP, Warszawa-Poznań.

Nowacki Wojciech, 2004: Ziemniak alternatywnym surowcem do produkcji bioetanolu, „Zeszyty Problemowe Postępów Nauk Rolniczych", 500, s. 45-56.

Pilarski Krzysztof, Kamil Witaszek, Jacek Dach, Damian Janczak, Magdalena Szymańska, 2012: Wplyw ilości zaszczepki bakteryjnej na dlugość rozruchu biogazowni, „Technika Rolnicza Ogrodnicza Leśna", nr 5.

Romuniak Wacław, Domasiewicz Tadeusz, 2014: Substraty dla biogazowni rolniczych, Wyd. Hortpress Sp. z o.o.

Szulc Robert, Jacek Dach, Florian Adamczyk, Damian Janczak, Jakub Lenarczyk, Ilona Rzeźnik, Wojciech Rzeźnik, Zbyszek Zbytek, 2014: Kierunki rozwoju ekoenergetyki w polskim rolnictwie. Polskie Towarzystwo Inżynierii Rolniczej w Krakowie, Kraków.

Tytko Ryszard, 2014: Urzadzenia i systemy energetyki odnawialnej, wydanie IV, Kraków, s, 576-579. Ustawa o odnawialnych źródtach energii z dnia 20 lutego 2015 r. Dz.U. 2015.87.478.

Zgórska Kazimiera, 2010: Wszechstronność wykorzystania bulw ziemniaka, „Ziemniak Polski”, s. 52-55.

\section{Sylwia Bartnikowska, Wojciech Czekała, Andrzej Lewicki, Anna Olszewska, Anna Smurzyńska, Michat Brzoski \\ POTATOES AS A POTENTIAL SUBSTRATE FOR A BIOGAS POWER PLANT}

\section{Summary}

Potato (Solanum tuberosum) is a very versatile vegetable, largely used as food for human, animal feeding and as well classified as industrial plant. Waste from processing potatoes can be used for energy purposes such as: liquid fuels or a combined production of electricity and heat from biogas production by anaerobic digestion. In order to test the biogas potential of potato waste an experiment were conducted at the laboratory of Eco technology of the Poznan University of Life Sciences. The treatments: I-control, II raw potatoes, III-steamed potatoes, $I V$-raw potato skins, $V$-steamed potato skins were tested in accordance to the German normalization DIN 38414 / S8. Additionally, economic aspects concerning the revenue obtained from the sale of electric energy produced according to biogas yields observed in laboratory were estimated.

Adres do korespondencji:

Mgr inż. Sylwia Bartnikowska

Uniwersytet Przyrodniczy w Poznaniu

Wydział Rolnictwa i Bioinżynierii, Instytut Inżynierii Biosystemów ul. Wojska Polskiego 50, 60-627 Poznań e-mail: syll.mal@vp.pl 